On the next day, Wednesday, Mr. Justice Bosanquet proceeded to pass the sentence upon him. He said, that Andrew, as a young man, night not have been aware of the offence he was committing, but he (the Judge ) felt it was necessary to inflict some punishment upon the present occasion, as a warning; and as he was unwilling to inflict a fine which the defendant wonld be unable to pay, he must submit to be imprisoned for a fortnight.

This is the first conviction under the Act since its passing in Aug ist, 1832.-Abridged from the Lincoln Mercury.

VERDICT WITHOUT SUFFICIENT EVIDENCE.

To the Editor,-Sir: On Tuesday, the 15 th instaut, I was sent for to see a purson named Moses Samuel, who was said to have taken arsenic. He certainly exhibited those symptoms which arise after taking a mineral poison, and, accordinely, I gave him an antidote, and cleansed the stomach, as well as I could, with the stoniach-pump. No medical aid was sought for uritil two hours and a halt had elapsed after taking the supposed poison, and the patient died in a short time after I had visited him. On the Thursday following, an inquest was held on the body by Mr. Stirling. The deceased's con fession, and the statement of a person who sold some arsenic to him, were the only matters put in as evidence that he had taken arsenic. A woman, with whom he had cohabited, said that she bought him some antimonial wine, which he took; but no proof was adduced that ant'monial wine was taken. I saved some of the contents of the stomach, but couli not detect arsenic by any of the usual tests. The medical evidence was, that the man probably died from some poison, but what kind the witness did not know, stating that the only means of ascer. taining the fact was by a post-mortem examination, which the jury did not think proper to enforce. $\Lambda$ verdict was returned, " Died from taking Arsenic." Now no person saw arsenic taken, and it could not be discovered by analyzation? Is not this a case which absolutely demanded a post-mortem examination? And would not a medical coroner have advised the jury to withold their verdict until it had been performed? I am sorry to say, that no such advice was given. $1 \mathrm{am}$, Sir, your obedient servant,

Benjamis Bernard Eardetey.

Islington, March 22, 1836.

\section{NORTH-LONDON HOSPITAL.}

GASTRODYNIA.

Wimliam Ovele, ætatis sure 38 , a farmer residing in Bedfordshire, admitted Dec. 22 , 1835 , under the care of Dr. Extorsox. He is of a spare habit, has never been addicted to drinking, and has usually enjoyed very good health. Two years since he was seized with severe pain at the epigastrium, not increased on pressure; loss of appetite, frequent vomiting, depression of spirits, palpitalion of heart, and obstinate constipation, which continuing for some time, and grazually increasing, obliged him to consult a medical practitioner, who supplied him with medicines, which afforded considerable relief, and, at the same time, orlered him to rub into the chest tartar-emetic ointment, the result of which was an abundant eruption of phlyzaceous pustules, which kealed wi h difficulty. In June, or July last, these symptoms became unexpectedly aggravated, and have been increasing to the date of almission.

II s smptorns now consist of dull, aching, and gnawing pain in the epigastric region, not increased on pressure or inspiration, aggravated after eating, but relieved for a short time by warm drinks, more particularly spirits, or wine and water. He is exceedingly lowspirited, cannot sleep, and is worse in the morning than at night. Complains of violent pain across the umbilical region, aris: ing, doubtlessly, from constipation, the howels having been confined for two or three days; his appetite is tolerable, although he occasionally vomits, and suffers from palpitation. No pain in head or chest, and auseultation reveals no abnormal condition of the thoracic viscera; urine passed in large quantities, but thick and turbid; tongue tolerably clean; pulse 84 , natural.

Bo Acidi Hydrocyanici $11 \mathrm{ij}$; ex Aquo Menthe Piperite f. 3 iss. 5 ta quaque bora sumatur.

Extract. Colocynth. Compos. gr. x, quaque nocte hora somni sumatur.

December 24. Pain of stomach relieved, but still complains of want of sleep.

28. Nuch better; bowels relieved daily ; pain in chest removed, but irritability of stomach continues. Auge Acidum Hydro. cyanicum ad liiiv.

January 2, 1836. Stomach irritable. Auge Acidum Hydrocyanicum ad It|v.

5. Acidi Hyd. Myi. 5ta quaque hora.

10. Although pain of stomach still remains, he expresses himself as considerably better than on his admission; buwels continue constipated.

\section{$\mathrm{R}$ Acidi Hydrocyanici ill vi;}

Eger Olei Crotone Tiglii 1il $\frac{x}{4}$, omni nocte sumatur.

January 16. Occasional pains, want of sleep, and great coldness of the back. Pergat in usu medicorum.

19. The dose of the acid not subduing the irritable condition of the stomach, increase the dose to nine minims; complains of 